\title{
MODELOWANIE RZECZYWISTYCH ZAKŁÓCEŃ WYSTEPUJĄCYCH PODCZAS LOTU NA PODSTAWIE ZAPISÓW REJESTRATORA POKŁADOWEGO
}

\begin{abstract}
W artykule przedstawiono metodę i wyniki modelowania zakłóceń dla celów obliczeń symulacyjnych w procesie syntezy właściwości pokładowego systemu sterowania statkiem powietrznym. Wykorzystano pomiary w locie do wyodrębnienia zakłóceń będących właściwością układu pomiarowego (szumy pomiarowe) oraz zakłóceń będących efektem oddziaływań zewnętrznych, np. turbulencji atmosferycznej. Opracowane algorytmy pozwalają na symulację działania pokładowego systemu sterowania w warunkach zbliżonych do występujących w rzeczywistym locie.
\end{abstract}

Słowa kluczowe: zakłócenia pomiarowe, sterowanie statkiem powietrznym, obliczenia symulacyjne

\section{Wprowadzenie}

Synteza układu sterowania samolotem odbywa się zazwyczaj na podstawie matematycznego modelu obiektu sterowania, bez uwzględniania właściwości układów pomiarowych oraz charakteru rzeczywistych zakłóceń będących wynikiem oddziaływania otoczenia (np. turbulencja) oraz uwzględniania właściwości kładów pomiarowych np. szybkozmiennych błędów pomiarowych. W praktyce eksploatacji statków powietrznych jakość sterowania samolotem w dużym stopniu zależy od rzeczywistych zakłóceń [3], w szczególności w przypadku obiektów latających o małych wymiarach, np. bezzałogowych statków powietrznych klasy mikro lub mini $[2,4,5]$. Charakter i wielkość zakłóceń pomiarowych (szumu pomiarowego) zależą od właściwości czujników pomiarowych oraz od zakłóceń generowanych przez obiekt latający. Własne szumy pomiarowe czujników zazwyczaj charakteryzują się dużą częstością i małą amplitudą w stanach ustalonych. Znacznie większe znaczenie mają zakłócenia generowane przez statek powietrzny, na pokładzie którego zabudowany jest czujnik (drgania od zespołu napędowego, zmienne pola elektromagne-

\footnotetext{
1 Autor do korespondencji/corresponding author: Andrzej Tomczyk, Politechnika Rzeszowska, al.
} Powstańców Warszawy 12, 35-959 Rzeszów, e-mail: A.Tomczyk@prz.edu.pl 
tyczne, itp.) lub otoczenie (warunki opływu), przy czym skutki tych zakłóceń zależeć będą od indywidualnej wrażliwości czujnika pomiarowego, ale również od miejsca i sposobu jego zabudowy, właściwości układu zasilania, stanu lotu, stanu otoczenia, itp. Podczas lotu nie sposób odróżnić błędów pomiarowych (statycznych oraz dynamicznych) od zakłóceń procesu sterowania pochodzących od działania czynników zewnętrznych otoczenia, w którym porusza się statek powietrzny [3]. Turbulencja, niestacjonarny opływ obiektu lub odkształcenia konstrukcji płatowca powodują zakłócenia stanu lotu mierzone przez czujniki i aktywujące układ sterowania. Jakość sterowania (stabilizacji wybranych zmiennych stanu) zależna będzie od wrażliwości układu na występujące zakłócenia.

\section{Metoda modelowania zakłóceń}

Zazwyczaj układy sterowania zaprojektowane dla idealnych stanów lotu (bez uwzględniania wpływu zakłóceń) wymagają modyfikacji (dostrojenia) w warunkach lotów rzeczywistych, co prowadzi do skomplikowania i wydłużenia zazwyczaj kosztownych badań w locie $[4,6]$. Proces ten można przyspieszyć i udoskonalić już na etapie projektowania układu sterowania wykorzystując do konstrukcji i testowania algorytmów sterowania modele rzeczywistych zakłóceń, w obecności których odbywa się realny lot statku powietrznego. W niniejszym opracowaniu zaproponowano zbudowanie bazy danych oraz algorytmów generowania modelowych zakłóceń bazujących na rzeczywistych pomiarach w locie wybranych klas statków powietrznych oraz określonych warunków lotu. Dane te powinny być przygotowane w taki sposób, aby na etapie weryfikacji jakości sterowania podczas badań symulacyjnych można było ocenić wpływ zakłóceń oraz dokonać modyfikacji układu sterowania [1,6]. Istotą proponowanej metody jest wydzielenie efektów zakłóceń zewnętrznych i pomiarowych z zarejestrowanych w locie sygnałów czujników pokładowych. Dane te będą użyteczne przede wszystkim dla analizy właściwości układu sterowania samolotu tej samej klasy co samolot użyty w locie pomiarowym oraz w zbliżonych warunkach lotu. Jednak dysponując odpowiednio bogatą bazą danych z lotów pomiarowych można przygotować bibliotekę procedur symulacji zakłóceń reprezentatywną dla określonej grupy zadań projektowych. W szczególności można posłużyć się danymi zarejestrowanymi podczas lotu statku powietrznego, dla którego projektowany jest dany układ sterowania.

Dane zapisane w pamięci rejestratora pokładowego zawierają informację o mierzonych wielkościach fizycznych na które nałożone są zakłócenia generowane $\mathrm{w}$ systemach pomiarowych oraz zakłócenia pochodzące od wymuszeń zewnętrznych względem układu pomiarowego. Należy zatem posłużyć się algorytmem, który pozwoli na oddzielenie zakłóceń od sygnału użytecznego. Niestety, nie jest dostępna informacja o ,idealnych” wartościach mierzonych zmiennych. Stałowartościowe lub wolnozmienne (w odniesieniu do właściwości dy- 
namicznych sterowanego obiektu) błędy (zakłócenia) pomiarowe nie wpływają w widoczny sposób na dynamiczną jakość sterowania. W niniejszym opracowaniu modelowana jest szybkozmienna składowa zakłóceń pomiarowych, która ma znaczący wpływ na jakość przejściowych procesów sterowania. Dla wydzielenia tej składowej zaproponowano aproksymację danych pomiarowych funkcjami ciągłymi, których parametry dobrane będą odpowiednio do analizowanych zmiennych pomiarowych. W zależności od stanu lotu oraz charakterystycznych właściwości mierzonego sygnału (pasma przenoszenia obiektu dynamicznego) do aproksymacji ,idealnych” wartości mierzonych sygnałów zastosowany zostanie wielomian odpowiedniego stopnia, rozpięty na wybranym przedziale czasu rejestracji.

a)

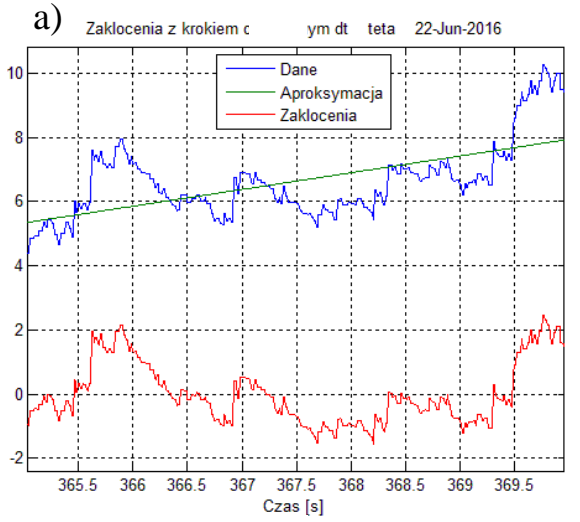

c)

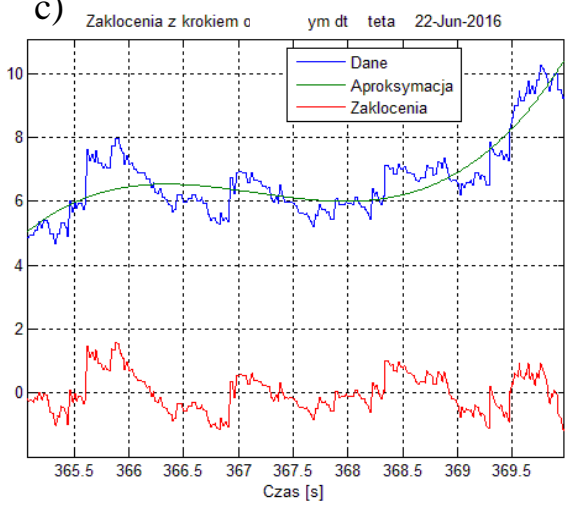

b)

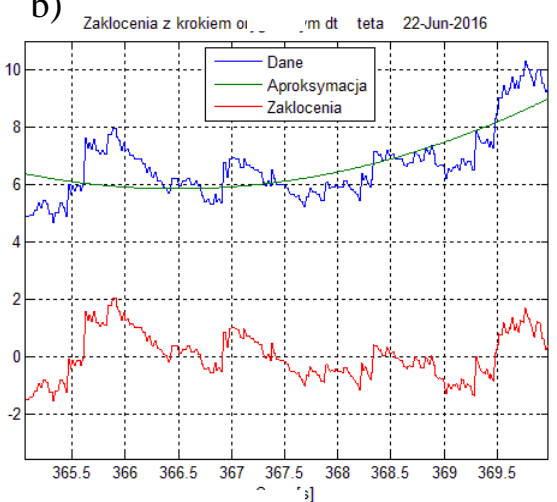

d)

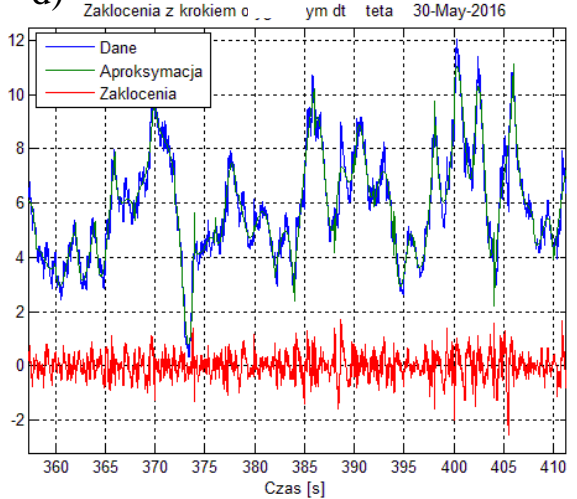

Rys. 1. Aproksymacja danych pomiarowych kąta pochylenia wielomianami odpowiednio pierwszego (a), drugiego (b) i trzeciego stopnia (c, d)

Fig. 1. Approximation of the pitch angle measurement data by polynomials of the first (a), second (b) and third degree (c, d), respectively

Na rysunku 1 przedstawiono efekty wydzielenia zakłóceń działających na samolot wraz z zakłóceniami pomiarowymi dla przypadków różnych stopni wielomianów aproksymacyjnych. Dane pomiarowe zostały zarejestrowane 
w locie samolotu Piper Seneca V w warunkach umiarkowanej turbulencji. Odpowiednio do charakteru zmian obserwowanej wielkości należy dobrać stopień wielomianu aproksymującego oraz przedział aproksymacji. Dogodną metodą postępowania jest skorzystanie $\mathrm{z}$ funkcji sklejanych; odpowiednie procedury obliczeniowe dostępne są w pakiecie symulacyjnym MATLAB. Opracowane programy obliczeniowe pozwalają na wybór metody aproksymacji danych pomiarowych, jak również wybór kroku czasowego zapisu zakłóceń, który może być różny od kroku rejestracji danych. Pozwala to na wykorzystanie zbioru modelowych zakłóceń w programach symulacyjnych o różnym kroku obliczeń, w szczególności w przypadku symulacji procesu sterowania w czasie rzeczywistym, z zadaną częstością repetycji obliczeń. Zbiór ten może zawierać tablice danych o zakłóceniach dla różnych stanów lotu, konfiguracji samolotu czy stanu burzliwości atmosfery.
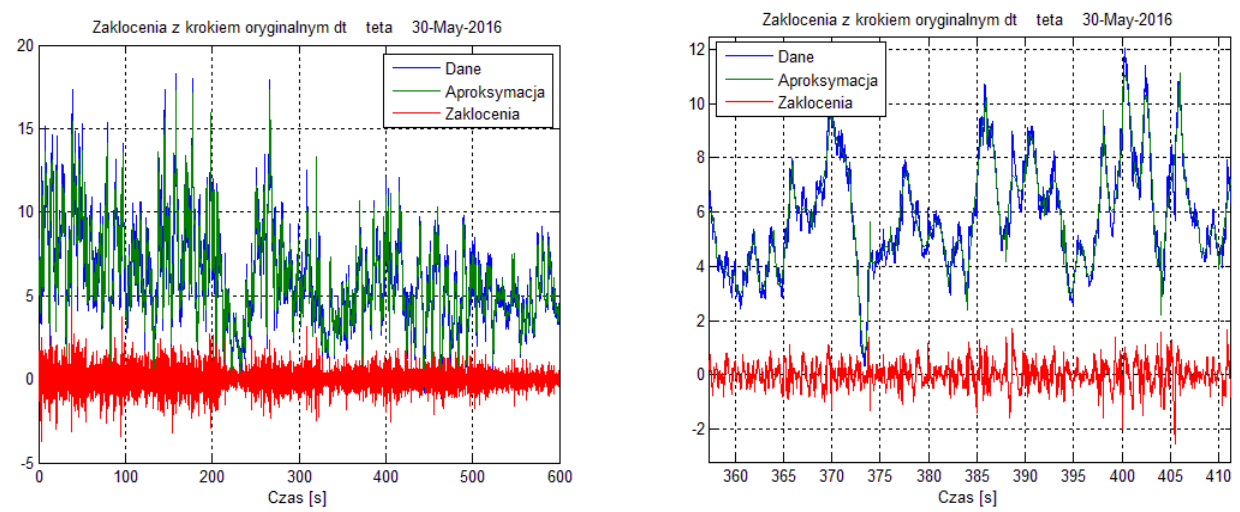

Rys. 2. Zakłócenia w kanale pomiarowym kąta pochylenia [st]

Fig. 2. Disturbances in measuring channel of the pitch angle [deg]
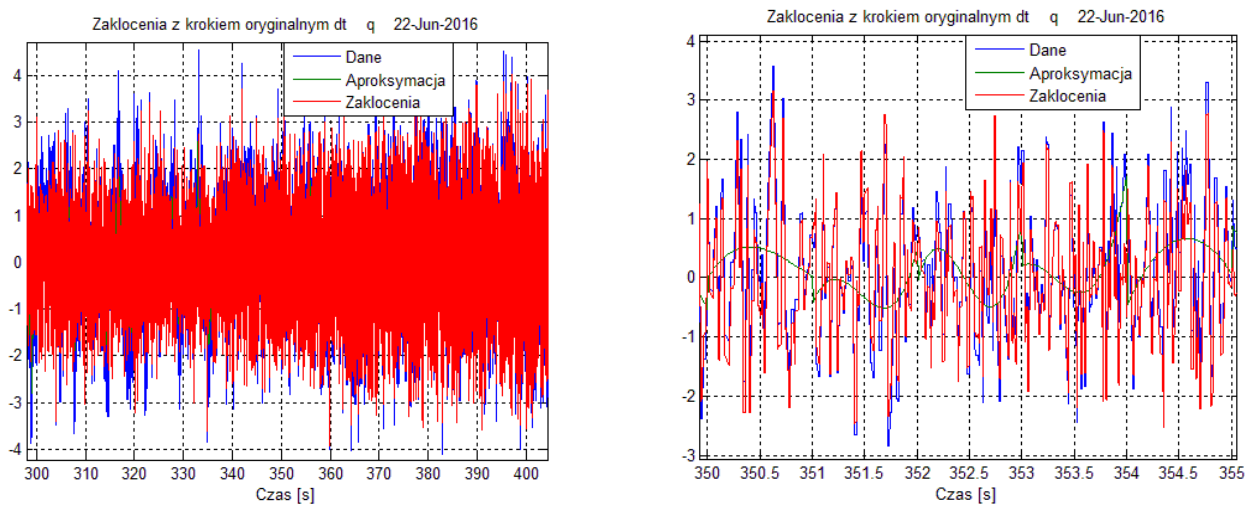

Rys. 3. Zakłócenia w kanale pomiaru prędkości kątowej pochylania [st/s]

Fig. 3. Disturbances in measuring channel of the pitch rate [deg/s] 
Rysunki 2-7 przedstawiają przykładowe zbiory zakłóconych mierzonych zmiennych stanu samolotu Piper Seneca V. Zastosowane zostały wielomiany trzeciego stopnia o przedziałach aproksymacji dobranych odpowiednio do charakteru obserwowanej zmiennej oraz właściwości dynamicznych samolotu. Przykładowo dla kąta pochylenia przedział aproksymacji ustalono na $1 / 2$ okresu oscylacji krótkookresowych, a dla pomiaru prędkości IAS 1/2 okresu oscylacji fugoidalnych, jeśli nie występowały energiczne manewry zmiany kąta toru lotu.

Uwzględnienie wpływu zakłóceń ma szczególne znaczenie w przypadku obiektów o nieliniowych charakterystykach lub opisanych układem nieliniowych równań różniczkowych lub/oraz uwzględniających nieliniowości o charakterze strukturalnym, jak ograniczenie kąta wychylenia i prędkości wychylania sterów aerodynamicznych. Wpływ zakłóceń szczególnie widoczny jest $\mathrm{w}$ przypadku stosowania redundancji analitycznej pomiarów, tj. obliczania niemierzalnych wartości zmiennych stanu na podstawie dostępnych pomiarów. W takim przypadku precyzja sterowania ulega pogorszeniu i obecność zakłóceń może w istotny sposób wpływać na jakość sterowania a nawet stabilność systemu. W fazie projektowania systemu sterowania oraz badań laboratoryjnych „Hardware-in-the-loop-simulation" symulacja funkcjonowania systemu w obecności zakłóceń pozwala zmodyfikować (dostroić) układ sterowania w taki sposób, aby uzyskać akceptowalną odporność systemu na wpływ zakłóceń.
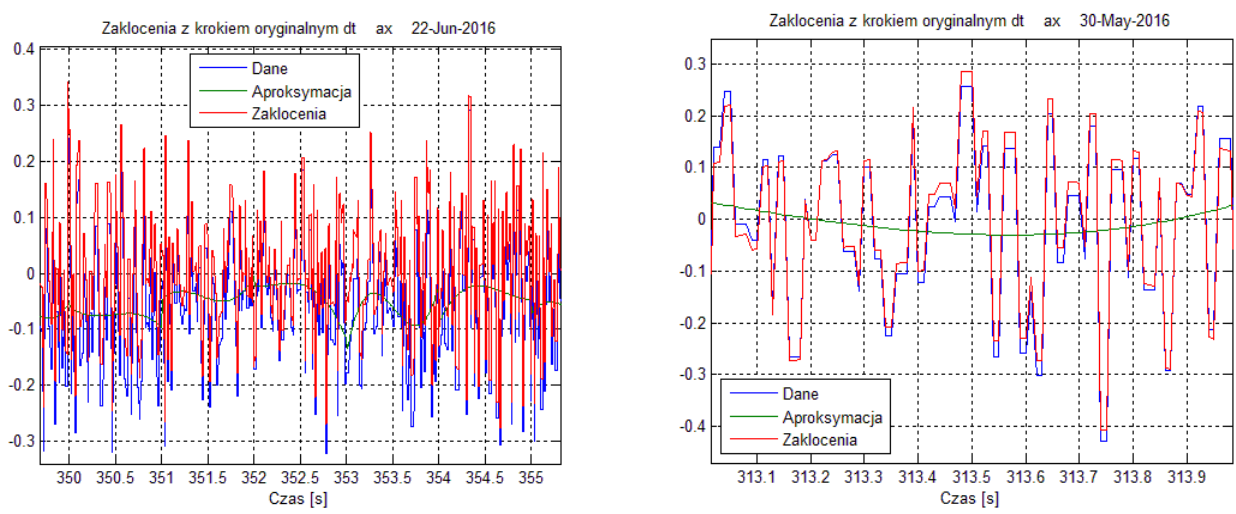

Rys. 4. Zakłócenia w kanale pomiaru przyspieszenia wzdłużnego [m/s $\left.\mathrm{s}^{2}\right]$

Fig. 4. Disturbances in measuring channel of the longitudinal acceleration $\left[\mathrm{m} / \mathrm{s}^{2}\right]$

Rysunek 8 przedstawia sposób sterowania kątem pochylenia podczas symulacji sterowania wysokością lotu samolotu PZL M20 Mewa. Analizowano przypadek, gdy dostępny jest pomiar kąta pochylenia oraz przypadek, gdy wartość kąta pochylenia jest estymowana na podstawie prędkości pionowej, prędkości lotu oraz szacowanej wartości kąta natarcia. W modelu symulacyjnym uwzględniono nieliniowe właściwości mechanizmu wykonawczego wychylającego ster wysokości. 

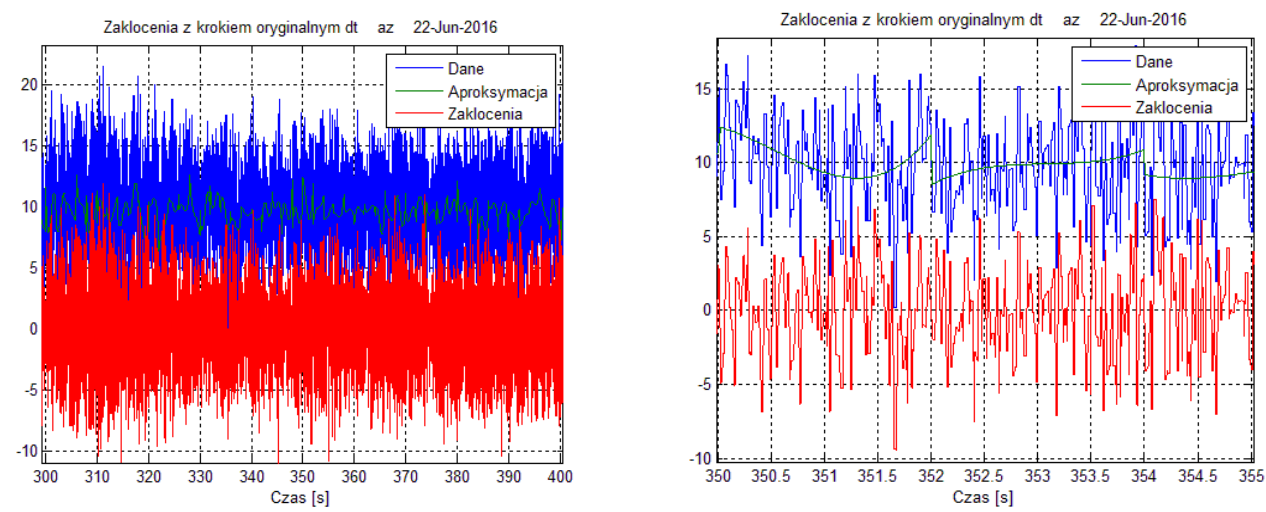

Rys. 5. Zakłócenia w kanale pomiaru przyspieszenia pionowego $\left[\mathrm{m} / \mathrm{s}^{2}\right]$

Fig. 5. Disturbances in measuring channel of the vertical acceleration $\left[\mathrm{m} / \mathrm{s}^{2}\right]$
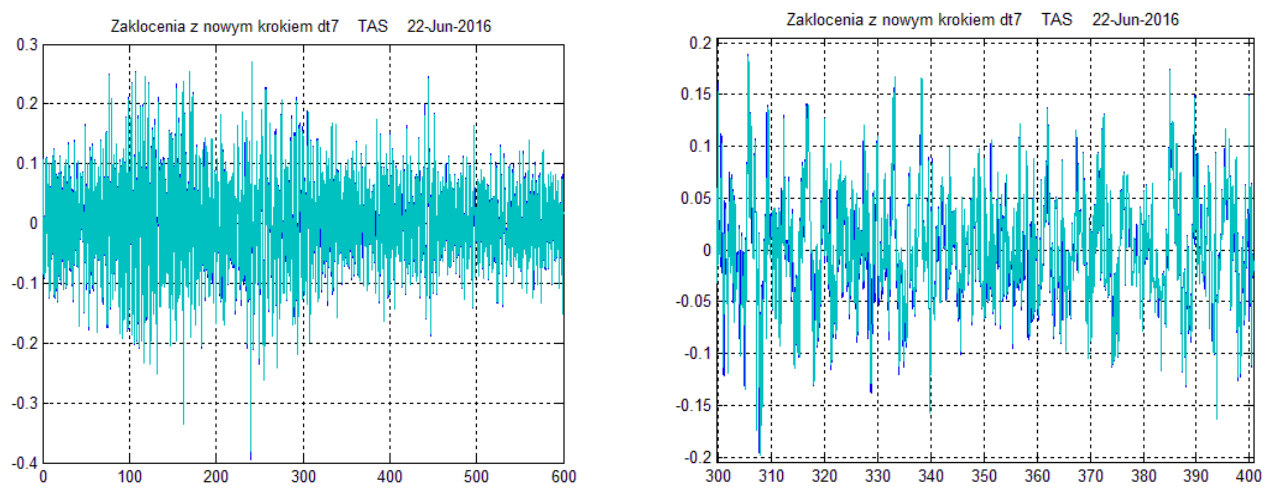

Rys. 6. Zakłócenia w kanale pomiaru prędkości rzeczywistej TAS [m/s]

Fig. 6. Disturbances in measuring channel of the true airspeed - TAS $[\mathrm{m} / \mathrm{s}]$
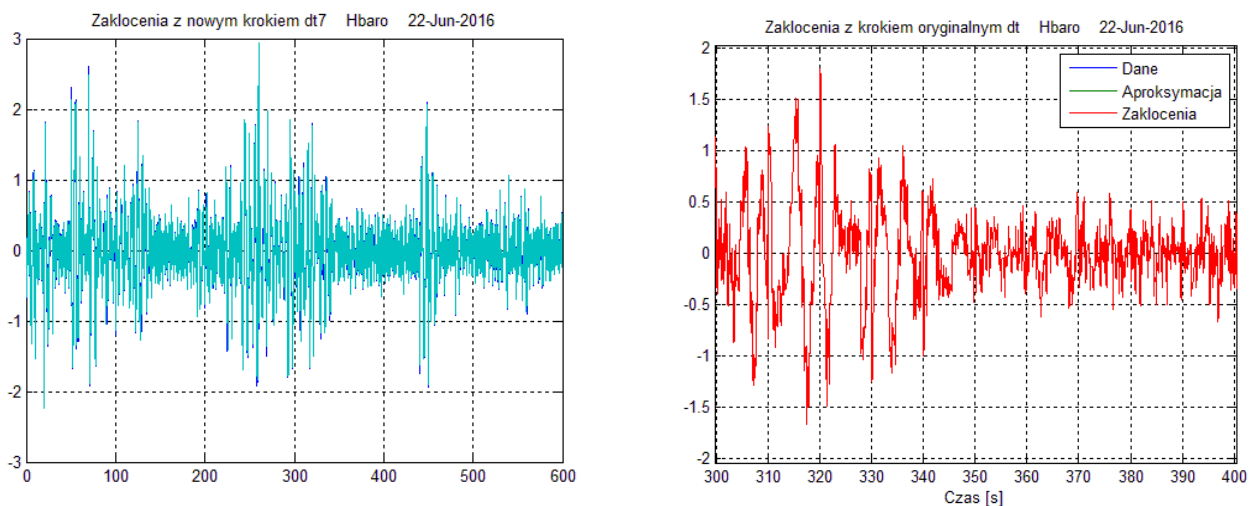

Rys. 7. Zakłócenia w kanale pomiaru barometrycznej wysokości lotu [m]

Fig. 7. Disturbances in measuring channel of the altitude [m] 


\section{Podsumowanie}

Proponowana metoda została wykorzystana na stanowisku badawczym typu „Hardware-in-the-loop-simulation” do weryfikacji poprawności oraz oceny jakości sterowania w warunkach symulujących rzeczywiste właściwości pokładowego systemu pomiarowego oraz oddziaływania zakłóceń zewnętrznych. Idealne (teoretyczne) wartości zmiennych stanu będące rozwiązaniem równań różniczkowych opisujących właściwości dynamiczne sterowanego obiektu sumowane są z zakłóceniami zmierzonymi i zarejestrowanymi podczas rzeczywistego lotu. Możliwa była modyfikacja parametrów algorytmów sterowania samolotem w taki sposób, aby uzyskać statystycznie mniejsze wartości uchybów sterowania, a tym samym uzyskać lepszą jakość sterowania.
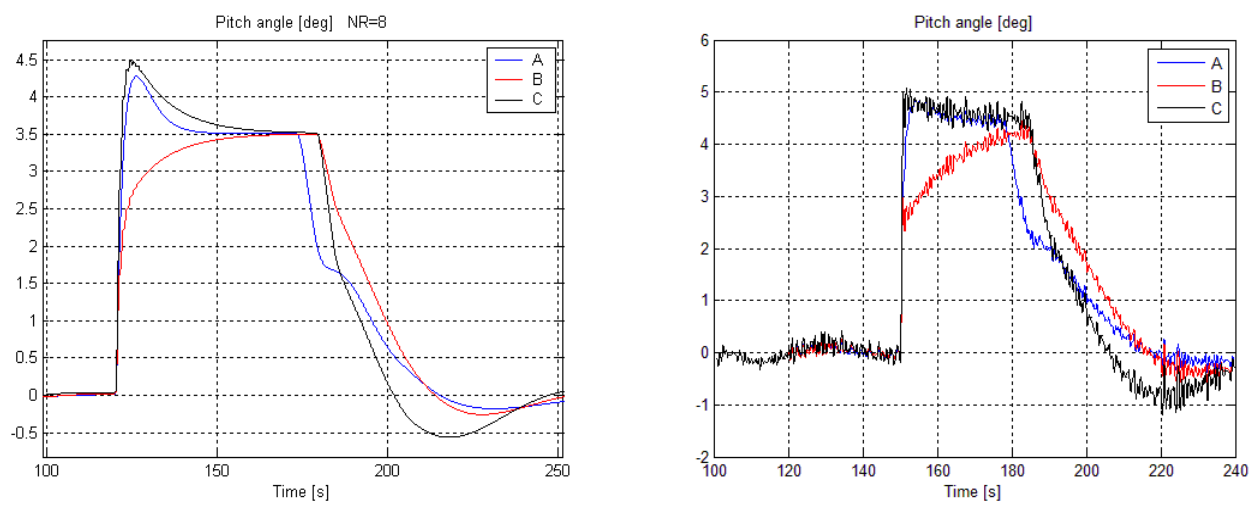

Rys. 8. Symulacja stabilizacji kąta pochylenia $\left[{ }^{0}\right]$ podczas sterowania wysokością lotu bez wpływu zakłóceń oraz z uwzględnieniem zakłóceń (po prawej): A - sterowanie na podstawie pomierzonej wartości kąta pochylenia, B - rzeczywisty kąt pochylenia, C - estymowany kat pochylenia

Fig. 8. Simulation stabilization control the angle of the flight altitude without (left) and including distrbances (right): A - control based on the measured value of the pitch angle, B - real pitch angle $\mathrm{C}$ - estimated value of the pitch angle

\section{Podziękowania}

Niniejsze opracowanie było częściowo finansowane w ramach projektu badawczego (akronim MYSTERY) przez Narodowe Centrum Badań i Rozwoju w latach 2013-2016.

\section{Literatura}

[1] Allerton D.: Principles of Flight Simulation, AIAA Education Series, John Wiley \& Sons, 2009.

[2] Austin R.: Unmanned Aircraft Systems, UAVS Design, Development and Deployment, AIAA Education Series, John Wiley \& Sons, 2010.

[3] Jędrzejewski J.: Próby w locie samolotów lekkich, Biblioteka Naukowa Instytutu Lotnictwa, Nr 16, Warszawa 2001. 
[4] Kopecki G., Tomczyk A., Rzucidlo P.: Algorithms of Measurement System for a Micro UAV, Solid State Phenomena, Mechatronic Systems and Materials IV, 198 (2013) 165-170.

[5] McShea R.E.: Test and evaluation of aircraft avionics and weapon systems, AIAA Education Series, Scitech Publishing, Inc., 2010.

[6] Tomczyk A., Rzucidło P.: Systemy pośredniego sterowania dla samolotów ogólnego przeznaczenia, OW PRz, Rzeszów 2011.

\title{
MODELING REAL DISTURBANCES OBSERVED DURING THE FLIGHT ON THE BASIS OF ON-BOARD FLIGHT DATA RECORDING
}

\begin{abstract}
S u m m a r y
This paper presents the method and results of modeling disturbances for the purposes of simulation computations in the synthesis process of properties of flight-control system. In this method, the in-flight measurements were used for separation of disturbances of measuring system (measuring noise) and external disturbances caused by e.g., atmospheric turbulence. The developed algorithms enable the simulation of on-board control system operation in conditions of real flight.
\end{abstract}

Keywords: disturbances of measurement, aircraft control, simulation computations

Acknowledgement: The research project has been partly financed from a grant allocated by the National Centre for Research and Development in Poland for the years 2013-2016. (MYSTERY Project)

DOI: $10.7862 / \mathrm{rm} .2017 .10$

Otrzymano/received: 12.12 .2016

Zaakceptowano/accepted: 24.02.2017 